\title{
Lusioersily
}

\section{Human microvascular endothelial cellular interaction with atomic N-doped DLC compared with Si-doped DLC thin films}

Okpalugo, TIT., Murphy, H., Ogwu, AA., Abbas, GA., Ray, SC., Maguire, PD., McLaughlin, JAD., \& McCullough, RW. (2006). Human microvascular endothelial cellular interaction with atomic N-doped DLC compared with Sidoped DLC thin films. Journal of Biomedical Materials Research Part B: Applied Biomaterials, 78B(2), 222-229. https://doi.org/10.1002/jbm.b.30459

Link to publication record in Ulster University Research Portal

Published in:

Journal of Biomedical Materials Research Part B: Applied Biomaterials

Publication Status:

Published (in print/issue): 01/08/2006

DOI:

10.1002/jbm.b.30459

Document Version

Publisher's PDF, also known as Version of record

\section{General rights}

Copyright for the publications made accessible via Ulster University's Research Portal is retained by the author(s) and / or other copyright owners and it is a condition of accessing these publications that users recognise and abide by the legal requirements associated with these rights.

\section{Take down policy}

The Research Portal is Ulster University's institutional repository that provides access to Ulster's research outputs. Every effort has been made to ensure that content in the Research Portal does not infringe any person's rights, or applicable UK laws. If you discover content in the Research Portal that you believe breaches copyright or violates any law, please contact pure-support@ulster.ac.uk. 


\title{
Human Microvascular Endothelial Cellular Interaction With Atomic N-Doped DLC Compared With Si-Doped DLC Thin Films
}

\author{
T. I. T. Okpalugo, ${ }^{1}$ H. Murphy, ${ }^{1}$ A. A. Ogwu, ${ }^{2}$ G. Abbas, ${ }^{1}$ S. C. Ray, ${ }^{3}$ P. D. Maguire, ${ }^{1}$ J. McLaughlin, ${ }^{1}$ \\ R. W. McCullough ${ }^{4}$ \\ ${ }^{1}$ NIBEC, School of Electrical and Mechanical Engineering, University of Ulster, United Kingdom \\ ${ }^{2}$ Thin Film Centre, University of Paisley, United Kingdom \\ ${ }^{3}$ Instituto de Ciencia de Materiales de Madrid, CSIC, Catoblanco, 28049, Madrid, Spain \\ ${ }^{4}$ Atomic and Molecular Physics Department, Queens University of Belfast, United Kingdom
}

Received 2 April 2005; revised 16 July 2005; accepted 3 August 2005

Published online 16 March 2006 in Wiley InterScience (www.interscience.wiley.com). DOI: 10.1002/jbm.b.30459

\begin{abstract}
This article reports results of endothelial cell interaction with atom beam source N-doped a-C:H (diamond-like carbon, DLC) as it compares with that of Si-doped DLC thin films. The RF plasma source exhibits up to $40 \% \mathrm{~N}$-dissociation and $\mathrm{N}$-atomic fluxes of $\sim 0.85 \times 10^{18}$ atoms/s, which ensures better atomic nitrogen incorporation. Two different types of nitrogen species (with and without the use of sweep plates to remove charged ions) were employed for nitrogen doping. The number of attached endothelial cells is highest on Si-DLC, followed by the N-DLC (where the sweep plates were used to remove ions), the N-DLC (without the use of sweep plates), undoped DLC, and finally the uncoated sample. The contact angle values for these films suggest that water contact angle is higher in the atomic nitrogen neutral films and Si-DLC films compared to the ionized-nitrogen specie doped films and undoped DLC thin films, suggesting that the more hydrophobic films, semiconducting films, and film with relieved stress have better interaction with human microvascular endothelial cells. It seems evident that $\mathrm{N}$-doping increases the Raman $I_{\mathrm{D}} / I_{\mathrm{G}}$ ratios, whereas $\mathrm{N}$-neutral doping decreases it slightly and Si-doping decreases it even further. In this study, lower Raman $I_{D} / I_{G}$ ratios are associated with increased $\mathrm{sp}^{3} / \mathrm{sp}^{2}$ ratio, an increased $H$ concentration, photoluminescence intensity, and a higher endothelial cellular adhesion. These investigations could be relevant to biocompatibility assessment of nanostructured biomaterials and tissue engineering. (C) 2006 Wiley Periodicals, Inc. J Biomed Mater Res Part B: Appl Biomater 78B: 222-229, 2006
\end{abstract}

Keywords: biocompatibility/hard tissue; carbon coatings; cell-material interactions; endothelial cells; surface modification/characterization

\section{INTRODUCTION}

The assessments of the biocompatibility of potential biomaterials used in nanotechnology for nanostructured medical devices could be very challenging at the scales down to the nanometer. A direct and distinct approach to this biocompatibility assessment is to examine separately all the individual materials before their integration into the nanostructured device, and afterwards to assess the biocompatibility of the finished device as a unit.

Diamond-like carbon (DLC) and its doped hybrids form a class of potential biomaterials that can find useful application

Correspondence to: T. I. T. Okpalugo (e-mail: thomas@nibec-s1.nibec.ulst.ac.uk) (ㄷ) 2006 Wiley Periodicals, Inc. in nanostructured device fabrication, as the properties of this group of materials depend on the processing/deposition parameters or the modifications employed. These processing parameters include the bias voltage, power, pressure, source gases employed, the dopants, and the postdeposition modifications such as thermal annealing induced microstructural atomic rearrangements. DLC (s) are readily available amorphous carbon materials used for surface modifications of various bulk materials and nanodevice fabrication. Its properties fall within those of natural pure crystalline graphite on one hand and diamond on the other. Interest in the use of DLC is particularly high due to its high hardness, scratch resistance, corrosion resistance, ultrasmoothness, ability to coat various complex shapes, and variable electrical properties as well as variable surface energy. Nitrogen incorporation into DLC reduces the water contact angle (increases the 
surface energy), ${ }^{1}$ though it seems that $\mathrm{N}$-neutral doping has increased the contact angle slightly in this study. Nitrogen incorporation has also led to reduction of typically high internal compressive stress of DLC and has resulted in improve thermal stability of the film. ${ }^{2}$ Silicon incorporation on the other hand is known to reduce the DLC typically high internal compressive stress, improve the adhesion and mechanical properties, increase the $\mathrm{sp}^{3}$ to $\mathrm{sp}^{2}$ ratio (because silicon does not form $\pi$ bonds), reduce the size of graphite-like islands, ${ }^{3}$ and increase the water contact angle. The band gap increase and the contact potential difference (CPD) decrease in Si-DLC have been reported to be due to silicon and hydrogen incorporation, suggesting a high trap density, with possible contribution from changes in the band gap or surface charge. ${ }^{4}$

In this study, we investigate the effects of different types of dopants species: nitrogen atom species, mixture of nitrogen atoms and ions or silicon on the biocompatibility of DLC, based on the cellular attachment of human microvascular endothelial cells (HMEC). We have previously studied the mechanical properties of Si-doped DLC (a-C:H:Si), using in situ doping during deposition. However, in situ doping via nitrogen incorporation can often lead to $\mathrm{CN}$-type films that differ significantly from a-C:H. Therefore, doping is undertaken postdeposition using a remote RF plasmas source of nitrogen atoms and ions. The ions can be removed using a transverse electric field, enabling a pure atomic $\mathrm{N}$ flux onto a-C:H surface. Because such flux is low energy (thermal), disruption of the a-C:H lattice is expected to be minimal. The diffusion of the nitrogen species and subsequent bonding with the a-C:H film is predicted by the X-ray photoelectron spectroscopy (XPS) and secondary ion mass spectroscopy (SIMS) techniques. We used HMECs because at the microvascular level where most cellular-biomaterials interactions occur, these cells play key roles in the blood intravascular inner wall linings to keep the blood flowing without clotting. The material-micro-vascular endothelial cellular interaction could therefore be related inversely to those of platelets (in vitro and in vivo), since increased platelets aggregation/adhesion on a material could be associated with increased potential of a material to induce clotting, while increased endothelialmaterial adhesion could be associated on the other hand with an increased potential of a material not to induce clotting, and

TABLE I. Operating Conditions for (A) RF Plasma Source for Atomic Nitrogen Postdeposition Doping of a-C:H (DLC), and for (B) PECVD for DLC and Si-DLC Deposition

\begin{tabular}{lcc}
\hline Operating Conditions & (A) RF Plasma Source & (B) PECVD \\
\hline Power $(\mathrm{W})$ & 500 & 140 \\
Reflected power $(\mathrm{W})$ & 25 & 5 \\
Sweep plate voltage $(\mathrm{V})$ & $100-120$ & - \\
Bias voltage $(\mathrm{V})$ & - & 400 \\
Deposition temperature $\left({ }^{\circ} \mathrm{C}\right)$ & $<100$ & 25 \\
Source temperature $\left({ }^{\circ} \mathrm{C}\right)$ & 300 & - \\
Pressure (torr) & 0.3 & $\sim 7 \times 10^{3}$ \\
Atomic flux $($ atoms $/ \mathrm{sec})$ & $0.8 \times 10^{18}$ & - \\
Exposure time $(\mathrm{h})$ & $1-2.5$ & $\sim 0.1$ \\
\hline
\end{tabular}

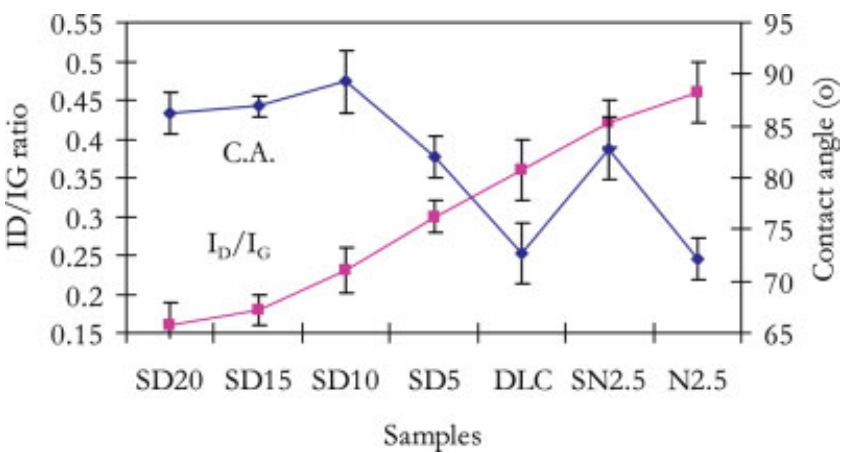

Figure 1. The Raman $\mathrm{I}_{\mathrm{D}} / \mathrm{I}_{\mathrm{G}}$ ratios and the water contact angles of a-C:H:N (N2.5, nitrogen doped for $2.5 \mathrm{~h}$ and SN2.5, = N neutral doped for 2.5 h); a-C:H (DLC); and a-C:H:Si (SD5-20, TMS flow rate of 5-20 $\mathrm{sccm}$ ) thin films. [Color figure can be viewed in the online issue, which is available at www.interscience.wiley.com.]

vice versa. ${ }^{5,6}$ We employed X-ray photoelectron spectroscopy (XPS), secondary ion mass spectroscopy (SIMS) data not presented in this paper, Raman spectroscopy (Raman), optical contact angle meter, and scanning electron microscopy (SEM) for characterization.

\section{EXPERIMENTAL DETAILS}

The DLC was synthesized by RF $13.56 \mathrm{MHz}$ plasma-enhanced chemical vapor deposition (PECVD) employing acetylene and argon as source gases (and tetramethylsilane, TMS for silicon doping to obtain Si-DLC). Afterwards, some of the deposited DLC thin films were then subjected to postdeposition nitrogen doping using an atomic nitrogen flux from an RF plasma source exhibiting up to $40 \%$ nitrogen dissociation and an atomic fluxes of $\sim 0.85 \times 10^{18}$ atoms/s. ${ }^{7}$ The RF plasma source is an ultrahigh vacuum (UHV) compatible source. The source consists of pyrolytic boron nitride (PBN) cylindrical plasma tube, surrounded by water-cooled RF coil operating at $13.56 \mathrm{MHz}$. The RF operating levels are 200$500 \mathrm{~W}$ range. Pure nitrogen (research grade $99.998 \%$ purity) is introduced at a constant pressure. A "sweep plate" is employed to attract charged ions in cases where these are excluded from the doping species (samples named SN). Thus, the samples were either $\mathrm{N}$-doped or Si-doped for comparison with undoped a-C:H. Nitrogen doping involves either atomic species (named "SN") or mixture of nitrogen atoms and ions

TABLE II. Raman Spectral Parameters for N-DLC Thin Films

\begin{tabular}{lrrrc}
\hline Samples & Peak $\left(\mathrm{cm}^{-1}\right)$ & \multicolumn{1}{c}{$\begin{array}{c}\text { Intensity } \\
(\text { a.u })\end{array}$} & $\begin{array}{c}\text { FWHM } \\
\left(\mathrm{cm}^{-1}\right)\end{array}$ & $I_{D} / I_{G}$ Ratio \\
\hline SN (1 h) & $1362.53(\mathrm{D})$ & 841.32 & 281.25 & 0.419 \\
& $1546.19(\mathrm{G})$ & 2005.76 & 151.69 & \\
SN $(2.5 \mathrm{~h})$ & $1361.29(\mathrm{D})$ & 804.43 & 283.08 & 0.415 \\
& $1545.7(\mathrm{G})$ & 1938.65 & 152.34 & \\
$\mathrm{~N}(2.5 \mathrm{~h})$ & $1370.22(\mathrm{D})$ & 1027.22 & 288.28 & 0.455 \\
& $1547.3(\mathrm{G})$ & 2258.66 & 149.80 & \\
\hline
\end{tabular}


TABLE III. Atomic \% Composition, $I_{D} / I_{G}$ Ratio, and H Concentration on a-C:H and a-C:H:Si Based on XPS, Raman, and FTIR analysis (ref. 9)

\begin{tabular}{|c|c|c|c|c|c|c|c|}
\hline \multirow[b]{2}{*}{ Sample } & \multirow{2}{*}{$\begin{array}{l}\text { TMS flow } \\
(\mathrm{sccm})\end{array}$} & \multicolumn{3}{|c|}{$\begin{array}{c}\text { Composition (atm \%) From XPS } \\
\text { Measurements }\end{array}$} & \multirow{2}{*}{$\begin{array}{l}\left(I_{D} / I_{G}\right) \\
\text { Ratio }\end{array}$} & \multicolumn{2}{|c|}{$\begin{array}{l}\text { Hydrogen Concentration } \\
\qquad\left(\text { atoms } / \mathrm{cm}^{3}\right)\end{array}$} \\
\hline & & $\mathrm{C}$ & $\mathrm{Si}$ & $\mathrm{O}$ & & $\mathrm{Si}-\mathrm{H}_{\mathrm{n}}$ & $\mathrm{C}-\mathrm{H}_{\mathrm{n}}$ \\
\hline a-C:H:Si(SD5) & 05 & 69.42 & 10.18 & 20.40 & 0.30 & $2.2 \times 10^{21}$ & $4.2 \times 10^{22}$ \\
\hline a-C:H:Si (SD10) & 10 & 68.38 & 18.43 & 13.19 & 0.23 & $2.8 \times 10^{21}$ & $6.2 \times 10^{22}$ \\
\hline
\end{tabular}

(named "N"), via postdeposition exposure for up to $2.5 \mathrm{~h}$. The nitrogen atom flux is uncharged, and of thermal energy, thus penetration of the amorphous carbon matrix is likely to occur with limited damage. The postdeposition N-doping parameters are listed in Table I.

The thin films were characterized by XPS (Kratos XSAM 800 equipped with an energy analyzer. $\mathrm{Mg} \mathrm{K} \alpha \mathrm{X}$-ray source was set at $15 \mathrm{KeV}$ and $20 \mathrm{~mA}$ ), Raman spectroscopy (ISALabram $50 \mathrm{~mW}$ argon laser $(\lambda=514.53 \mathrm{~nm}))$, KSV CAM 200 optical contact angle meter (size of water drop $=5 \mu \mathrm{L}$ ), and the Hitachi S-3200N SEM.

\section{HMEC Culture}

The HMEC cultures were maintained in MCDB-131 supplement with L-Glutamine $(200 \mathrm{~m} M), 10 \%$ fetal calf serum (FCS), epidermal growth factor (EGF) (10 ng/mL), Penicillin (20 I.U/mL), and streptomycin $(20 \mu \mathrm{g} / \mathrm{mL})$. The cells were grown as monolayers in tissue culture flasks at $37^{\circ} \mathrm{C}$ under
$5 \% \mathrm{CO}_{2} / 95 \%$ air. Protein overcoatings on the cell monolayer were removed with two washings of phosphate-buffered saline (PBS). Trypsin solution was used for harvesting the cells for subculturing or for material testing. Shortly afterwards, the trypsin was inactivated by the use of MCDB-131 culture media, and by centrifugation, the supernatants were separated from the cells. Cells were used for material testing when they were about confluent. The samples were sterilized before they were taken into the hood and every normal culturing sterility precaution was taken throughout the experiment. About 3 $\times 10^{5}$ cells $/ \mathrm{mL}$ were seeded on top of the samples placed inside the petri dishes for about $6 \mathrm{~h}$, in the incubator. After incubation, the protein layer and unattached cells were removed by two washings of PBS, and afterwards the attached cells were fixed, dried, and prepared for SEM imaging.

The cell numbers were counted over an area of $600 \times 400$ $\mu \mathrm{m}^{2}$ on the SEM image of various samples by the use of UTHSCSA, Image Tool program. ${ }^{8}$

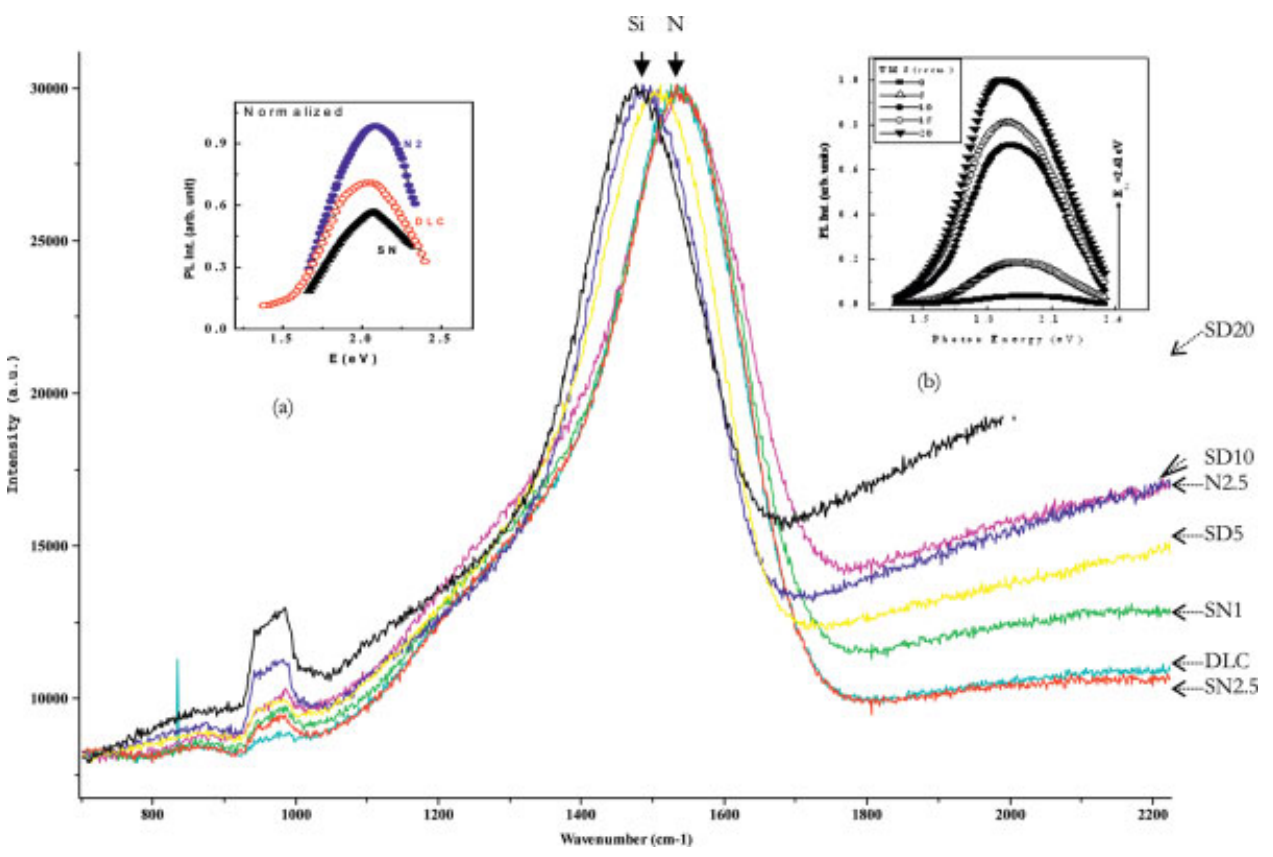

Figure 2. $\mathrm{PL}$ intensity/Raman spectra slope of a-C:H, a-C:H:N, and a-C:H:Si thin films. PL spectra of $\mathrm{N}$-DLC inset (a) and Si-DLC ref. 9 inset (b). [Color figure can be viewed in the online issue, which is available at www.interscience.wiley.com.] 


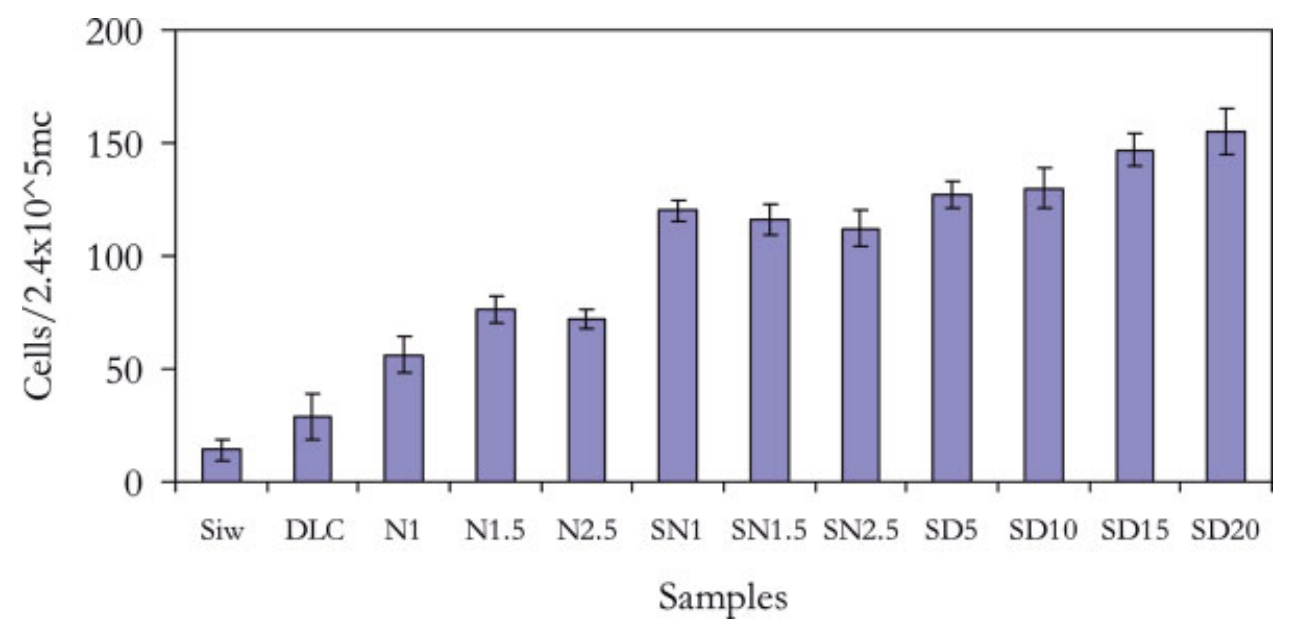

Figure 3. HMEC attachment per $2.4 \times 10^{5} \mu \mathrm{m}^{2}$ of (a) DLC and a-C:H:Si (SD5-20, 5-20 sccm of TMS flow) thin films compared to (b) a-C:H:N (doped with $\mathrm{N}$-neutrals) thin films. [Color figure can be viewed in the online issue, which is available at www.interscience.wiley.com.]

\section{RESULTS}

We relate the Raman features, including photoluminescence (PL) intensity, and the C-hybridization, the XPS-atomic percentage concentration, the bonding configuration based on the assignments derived from XPS data fitting, and the contact angle investigations to the endothelial cellular attachment to the aforementioned thin films.

\section{Water Contact Angle}

The results show higher water contact angle (Figure 1) for the N-DLC when the sweep plates were used and for Si-DLC samples generally (water contact angle $>80^{\circ}$ ). The water contact angle varies from $72.7^{\circ}$ (DLC) to $89.3^{\circ}$ with $\mathrm{Si}$ doping. However, for N-doping the variation is up to $82.8^{\circ}$ when the sweep plate is used. When the sweep plate is removed, the film is exposed to both ionic and atomic species and the contact angle tends to a lower value $72.1^{\circ}$.

\section{Vibrational Spectroscopy--Raman and PL Features}

The Raman $I_{\mathrm{D}} / I_{\mathrm{G}}$ ratios (Table II, Figure 1) seem to be highest in the N-DLC when no sweep plate is used. In Si-doped films the Raman $I_{\mathrm{D}} / I_{\mathrm{G}}$ ratios decreased (Table III, Figure 1) as the PL intensities increased with increasing amount of silicon and hydrogen (Table III) in the film. However, the PL intensity (or Raman slopes, Figure 2) in the $\mathrm{N}$-doped films seem to show a different behavior [Figure 2, inset (a)]. Si-doping, unlike N-doping, shows a downward shift in both the D- and G-peak positions (by $\sim 20-60 \mathrm{~cm}^{-1}$ ), with Raman shifts increasing as the amount of silicon and hydrogen increases (increased TMS flow rate) in the film. $\mathrm{N}$-doping shows slight upward shifts $\left(\sim 6 \mathrm{~cm}^{-1}\right.$ in G-peak and $\sim 10-12 \mathrm{~cm}^{-1}$ in D-peak positions). The Raman shift being lower in the neutrals/atomic nitrogen doped films compared to the films doped with ionic species included (Figure 2).

\section{X-Ray Photoelectron Spectroscopy}

The XPS elemental quantification seems not to show a significant difference in the atom percentage concentration in the "SN" and "N" category of samples. However, non-bonded N atoms are increased in the "SN" category (Table V). The oxygen content is approximately similar, though highest in the postdeposition N-doped films that is 15\% (DLC), 13-20\% (Si-DLC), and $\sim 20 \%$ for $\mathrm{N}$-doped samples. The CPD results suggest that the CPD decreased with increasing nitrogen exposure time ${ }^{11}$ as with increasing amount of silicon and hydrogen in the Si-DLC films. ${ }^{4}$

\section{Endothelial Cellular Interaction}

The results of the HMEC attachment on the various films show that Si-DLC exhibited highest number of endothelial cellular attachment, followed by the N-DLC where the ions were excluded (named "SN") from the doping species, the $\mathrm{N}$-DLC where the ions were included (named "N") in the doping species, and finally the undoped DLC thin films (Figure 3). Thus, the endothelial cellular interaction on the $\mathrm{N}$-DLC where the sweep plates were used (named "SN") seems to be better compared with when they were not used (Figures 3 and 5). Si-DLC (Figures 3 and 6) and either types of N-DLC seem to improve endothelial cellular interaction compared to the undoped DLC (Figures 3 and 6). Statistically, there is a significant difference (at 95\% confidence interval level, with $p<0.05$, paired $t$-test and Tukey test) between the samples, DLC and Si-DLC, DLC and N-DLC, DLC and N-DLC (SN-type), and between N-DLC (N-type) and N-DLC (SN-type) films. There are no significant difference for Si-DLC (SD) films doped with various TMS flow rates and equally no significant difference in "SN" or "N" films doped for various times. 

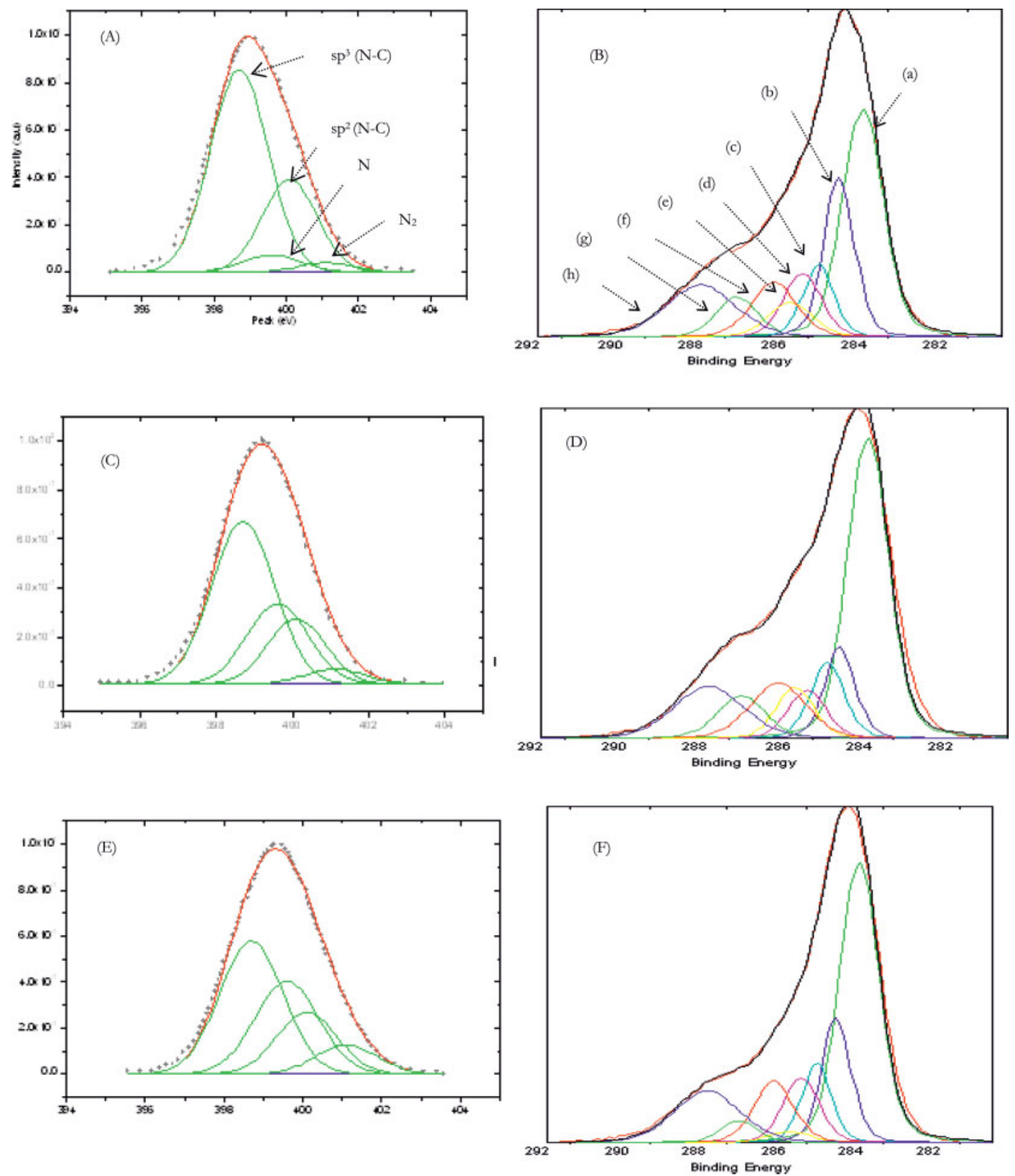

Figure 4. Deconvoluted XPS peaks: (a) N 1s, (b) C 1s, of sample doped with whole N-plasma for $2 \mathrm{~h}$ (N2), (c) N 1s, (d) C 1s of 'SN1'; (e) N 1s, and (f) C 1s of 'SN2.5' (samples doped with atomic/N-neutrals for $1 \mathrm{~h}$ and $2.5 \mathrm{~h}$ respectively); [details of (a)-(h) are shown in table V]. [Color figure can be viewed in the online issue, which is available at www.interscience.wiley.com.]

\section{DISCUSSION}

In both crystalline and amorphous materials, doping is achieved by introducing atoms interstitially or by substitution so as to change the local structure of the bonding of the host material. In amorphous materials large concentration of the dopant is required to compensate the existing traps and dangling bonds. ${ }^{12}$ It is not really obvious what is the effect of the "neutral-species- 


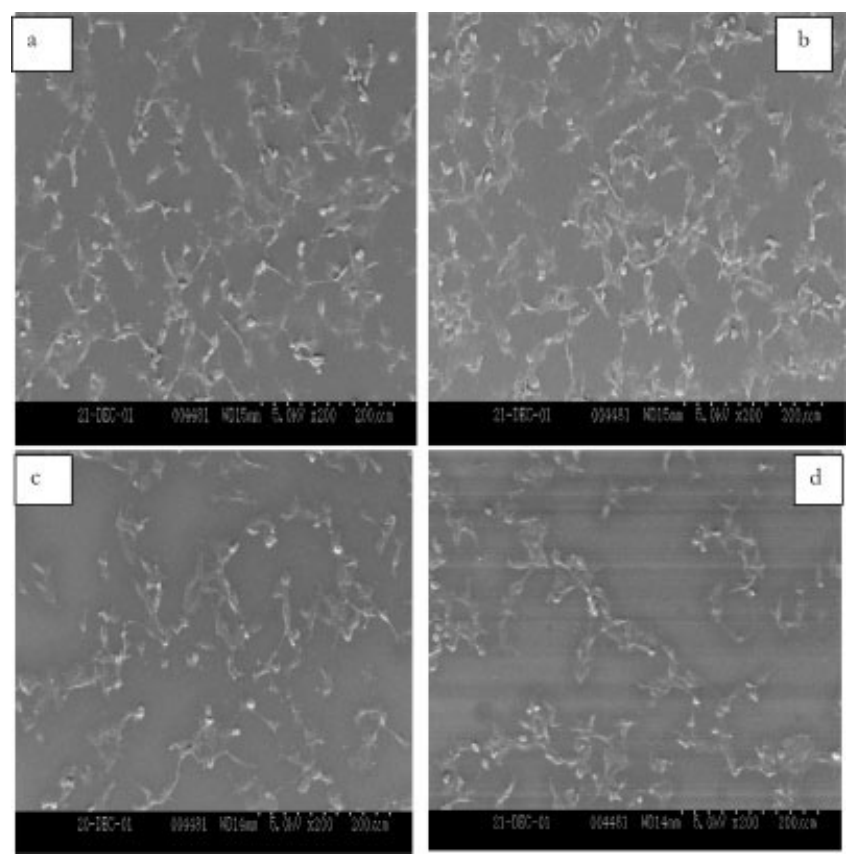

Figure 5. SEM micrographs of endothelial cell adhesion on a-C:H:N thin films, $\times 200$; (a) SN1 (1 h exposure to nitrogen with use of sweep plates); (b) SN2.5 (sweep plate for 2.5 h); (c) N1 (1 h, no sweep plate); and (d) N2.5 (2.5 h, no sweep plate used).

only" doping or the possible change in the microstructure resulting from this. However, it is expected that there could be a difference in the geometric and attachment cross sections of the neutral species compared to that of the charged species as well as a difference in the energy distribution function that could result in a possible difference in the atomic structure. However, the differences could be masked by the fact that the neutral species are usually the dominant population within the entire plasma species. Nitrogen incorporation has been used to improve the field emission property ${ }^{10}$ and electrical properties ${ }^{11}$ of DLC. Capacitance Kelvin and the I-V probes suggest that in the N-doped DLC (without the use of sweep plate) the CPD and the density of state (DOS) decreased, indicating a Fermi level rise. ${ }^{11}$ However, Kaukonen et al. ${ }^{13}$ suggested based on their density function theoretical (DFT) calculation that a single $\mathrm{N}$ atom substitution at an $\mathrm{sp}^{3}$ or $\mathrm{sp}^{2}$ site in an a-C subsurface layers increases the total density of states (TDOS) below the energy gap, resulting in Fermi energy $\left(E_{\mathrm{f}}\right)$ level moving down and the increase in work function. However, substitution on the $\mathrm{sp}^{1}$ and $\mathrm{sp}^{2}$ rings in the outer surface leads to TDOS increase near the conduction band edge with the Fermi level moving up and the work function decreasing. This decrease in the work function is thought to be dependent on the new states formed above the $E_{\mathrm{f}}$ following $\mathrm{N}$ substitution and a redistribution of the surface charges resulting in changes in the surface dipoles. It is not clear whether $\mathrm{N}$ substitution in this study is dominant at the $\mathrm{sp}^{1}, \mathrm{sp}^{2}$, or the $\mathrm{sp}^{3}$ sites in either types of N-doping or whether the "SN" atomic species substitute preferentially the $\mathrm{sp}^{1}$ and $\mathrm{sp}^{2}$ sites compared to the ionic $\mathrm{N}$ species. Nitrogen doping of a-C is known to increase the $\mathrm{sp}^{2} / \mathrm{sp}^{3}$ ratio and density function theoretical (DFT) calculations ${ }^{13}$ suggests that $\mathrm{N}$ atoms positioned at $\mathrm{a} \mathrm{sp}^{3}$ site decreases their coordination number with resulting $\mathrm{sp}^{2}$ $\mathrm{N}$ (or $\mathrm{N}$ with a nonplanar threefold coordination). Nitrogen incorporation into DLC normally reduces the contact angle (increases the surface energy), ${ }^{1}$ though it seems that $\mathrm{N}$-neutral specie ("SN") doping increased the contact angle in this study (Figure 1). Nitrogen incorporation has also led to reduction of typically high internal compressive stress of DLC and has resulted in improved thermal stability of the film. ${ }^{2}$ Silicon incorporation on the other hand is known to reduce the DLC typically high internal compressive stress, improve the adhesion and mechanical properties, increase the $\mathrm{sp}^{3}$ to $\mathrm{sp}^{2}$ ratio (because silicon does not form $\pi$ bonds), reduce the size of graphite-like islands, ${ }^{3}$ and increase the water contact angle (Figure 1). The band gap increase and the CPD decrease in Si-DLC have been reported to be due to silicon and hydrogen incorporation, suggesting a high trap density, with possible contribution from changes in the band gap or surface charge. ${ }^{4}$ It is suggestive that reduction in compressive stress in DLC following either silicon or nitrogen doping could contribute to improved endothelial cellular attachment to DLC thin films.

These preliminary results seem to suggest therefore that more hydrophobic films, with the following properties: decreased compressive stress, increased atomic networks, and decreased graphitic clusters as well as semiconductivity may be favorable to human microvascular endothelial cellular attachment. Other researchers have reported surface properties expressed in terms of hydrophobicity to be the key factor, dictating the type and conformation of adsorbed proteins and therefore the cell adhesion. The seeding of bovine thoracic endothelial cells on cellulose surfaces with increasing hydrophobicity resulted in increased endothelial cell adhesion and proliferation and decreased migration. ${ }^{14}$ Investigation on endothelial-specific cell adhesion to peptide sequences on different extra cellular matrix (ECM) molecules grafted on to various surfaces reveal that the arg-gluasp-val (REDV) sequence from fibronectin was selective for the adhesion of endothelial cells but not fibroblasts, smooth muscle cells, or activated platelets where other sequences like arg-glyasp (RGD), tyr-ile-ser-gly-arg (YISGR), or pro-asp-ser-gly-arg (PDSGR) were implicated. ${ }^{15}$ This implies that the behavior of platelets and endothelial cells to materials are different, but could be seen as being complementary; thus, the interaction of microvascular endothelial cells with materials could be related to those of platelets.

Raman intensity PL (indicating mainly $\mathrm{sp}^{3}$ coordination) was evident in especially a-C:H:Si thin films. Generally, the PL spectra band [Figure 2 inset (a) and (b)] are broad and structure less. The band of the luminescence peak for the Si-DLC films seems to shift toward a lower energy (Recall trend in the Raman shift) compared to those of N-DLC that seem to shift to higher energy (Figure 2). In general, features of PL in several amorphous semiconductors such as a-Si:H, a-C:H, a-C:H:Si, and $\mathrm{a}-\mathrm{C}: \mathrm{H}: \mathrm{N}$ are attributed to tail-to-tail states recombination of localized electron-hole pairs (EHPs). There is saturation of the carbon dangling bonds and recombination of EHPs within $\mathrm{sp}^{2}$ bonded clusters in $\mathrm{sp}^{3}$-bonded amorphous matrix. The PL intensity tends to increase with increasing hydrogen $(\mathrm{H})$ concentration (Table III, ref. 9) primarily due to the saturation of nonra- 
TABLE IV. XPS Atomic \% Concentration, FWHM, and Peak Positions of elements in a-C:H:N Thin Films

\begin{tabular}{lcccc}
\hline Samples & Element & Peak (eV) & FWHM (eV) & At. \% Conc. \\
\hline SN1 & C1s & 285.00 & 2.37 & 60.16 \\
& N1s & 399.80 & 2.45 & 17.90 \\
\multirow{4}{*}{ SN2.5 } & O1s & 532.40 & 2.82 & 21.94 \\
& C1s & 284.90 & 2.01 & 65.41 \\
& N1s & 400.10 & 2.52 & 14.22 \\
\multirow{2}{*}{2.5} & O1s & 532.80 & 2.83 & 20.38 \\
& C1s & 285.10 & 2.08 & 61.71 \\
& N1s & 400.00 & 2.55 & 16.34 \\
& O1s & 532.70 & 2.77 & 21.95 \\
\hline
\end{tabular}

diative recombination sites (for example dangling bonds). Although hydrogen is thought to be responsible for the PL in $\mathrm{a}-\mathrm{C}: \mathrm{H}$, it is likely that other dopant atoms by saturating the dangling bonds could contribute to the PL effects observed in this study. This is also related to loss of three-dimensional network bonding, caused by $\mathrm{C}-\mathrm{H}$ bond termination, and a polymeric $\mathrm{CH}_{2}$-bond formation. It seems difficult to establish, at this stage, a relationship between Raman PL (indicating mainly $\mathrm{sp}^{3}$ coordination bond) and endothelial cellular interaction. In- stead, the $\mathrm{sp}^{2}$ clusters sizes, graphitization, and the $\mathrm{sp}^{2} / \mathrm{sp}^{3}$ ratios could be more important in these cellular interactions. It is evident that $\mathrm{N}$-doping increases the Raman $I_{\mathrm{D}} / I_{\mathrm{G}}$ ratios, whereas Si-doping decreases it (Tables II and III, Figure 1). It seems that lower $I_{\mathrm{D}} / I_{\mathrm{G}}$ ratios indicative of increased atomic network formation, saturation of dangling bonds, decrease in graphitic cluster, and associated increased $\mathrm{sp}^{3} / \mathrm{sp}^{2}$ ratio or increase in hydrogen content (Table III) could improve endothelial cellular interaction. This is suggested from the results of Si-doped and N-neutral ("SN" species) doped films exhibiting comparatively lower Raman $I_{\mathrm{D}} / I_{\mathrm{G}}$ values and a higher number of endothelial cell attachment. However, it is still difficult to set out, in terms of units, the optimal boundary values of $I_{\mathrm{D}} / I_{\mathrm{G}}$ ratios for improved endothelial cellular interaction.

There seems to be no remarkable difference or trend observable from the C1s XPS analysis (Tables IV and V and Figure 4) for N-doping with only neutral species ("SN") when compared with its counterpart ("N"). However, the N1s XPS peak fitting suggests a much lower nonbonded atomic $\mathrm{N}(399.6 \mathrm{eV})$ and molecular nitrogen $(401.1 \mathrm{eV})$ concentration in the films doped with plasma including the ionic species and higher percentage concentration of both the $\mathrm{sp}^{3}-\mathrm{sp}^{2}$-bonded $(\mathrm{N}-\mathrm{C})$ fractions compared to the films doped with the atomic neutral species (Table

TABLE V. G4L1 (4-Gaussian-1-Lorentzian Product Function) Deconvolution of XPS Peak of a-C:H:N Thin Films

\begin{tabular}{|c|c|c|c|c|c|c|c|}
\hline \multicolumn{4}{|c|}{$\mathrm{C} 1 \mathrm{~s}$} & \multicolumn{4}{|c|}{$\mathrm{N} 1 \mathrm{~s}$} \\
\hline \multicolumn{8}{|l|}{ Sample N2.5 } \\
\hline (b) $\mathrm{sp}^{3} \mathrm{C}-\mathrm{C}$ & 285.2 & 0.9 & 17.6 & $\mathrm{~N}$ & 399.6 & 1.9 & 5.5 \\
\hline (c) $\mathrm{sp}^{2} \mathrm{C}_{3} \mathrm{~N} / \mathrm{sp}^{3} \mathrm{C}_{4} \mathrm{~N}$ & 285.6 & 0.9 & 7.9 & $\mathrm{sp}^{2}(\mathrm{~N}-\mathrm{C})$ & 400.1 & 1.8 & 27.7 \\
\hline (f) $\mathrm{sp}^{4} \mathrm{C}_{3} \mathrm{~N}_{2}$ & 286.8 & 1.3 & 8.8 & & & & \\
\hline (g) $\mathrm{C}=\mathrm{O} / \mathrm{NC}$ & 287.6 & 1.2 & 5.8 & & & & \\
\hline (h) $\mathrm{sp}^{3} \mathrm{C}_{2} \mathrm{~N}_{3}$ & 288.5 & 2.0 & 12.6 & & & & \\
\hline \multicolumn{8}{|l|}{ Sample SN1 } \\
\hline (a) $\mathrm{sp}^{2} \mathrm{C}=\mathrm{C}$ & 284.5 & 1.2 & 40.6 & $\mathrm{sp}^{3}(\mathrm{~N}-\mathrm{C})$ & 398.7 & 1.9 & 51.6 \\
\hline (f) $\mathrm{sp}^{4} \mathrm{C}_{3} \mathrm{~N}_{2}$ & 286.8 & 1.6 & 10.0 & & & & \\
\hline (g) $\mathrm{C}=\mathrm{O} / \mathrm{NC}$ & 287.6 & 1.4 & 6.6 & & & & \\
\hline (h) $\mathrm{sp}^{3} \mathrm{C}_{2} \mathrm{~N}_{3}$ & 288.5 & 2.0 & 11.6 & & & & \\
\hline \multicolumn{8}{|l|}{ Sample SN2.5 } \\
\hline (a) $\mathrm{sp}^{2} \mathrm{C}=\mathrm{C}$ & 284.5 & 1.2 & 41.3 & $\mathrm{sp}^{3}(\mathrm{~N}-\mathrm{C})$ & 398.7 & 1.9 & 42.7 \\
\hline (b) $\mathrm{sp}^{3} \mathrm{C}-\mathrm{C}$ & 285.2 & 0.9 & 13.8 & $\mathrm{~N}$ & 399.6 & 1.9 & 29.8 \\
\hline (c) $\mathrm{sp}^{2} \mathrm{C}_{3} \mathrm{~N} / \mathrm{sp}^{3} \mathrm{C}_{4} \mathrm{~N}$ & 285.6 & 0.9 & 8.8 & $\mathrm{sp}^{2}(\mathrm{~N}-\mathrm{C})$ & 400.1 & 1.8 & 18.7 \\
\hline (d) $\mathrm{C}-\mathrm{O}$ & 286.1 & 1.1 & 8.7 & $\mathrm{~N}_{2}$ & 401.1 & 1.8 & 8.8 \\
\hline (e) $\mathrm{sp}^{2} \mathrm{C}_{2} \mathrm{~N}_{2}$ & 286.3 & 1.3 & 1.6 & & & & \\
\hline (f) $\mathrm{sp}^{4} \mathrm{C}_{3} \mathrm{~N}_{2}$ & 286.8 & 1.3 & 9.1 & & & & \\
\hline
\end{tabular}




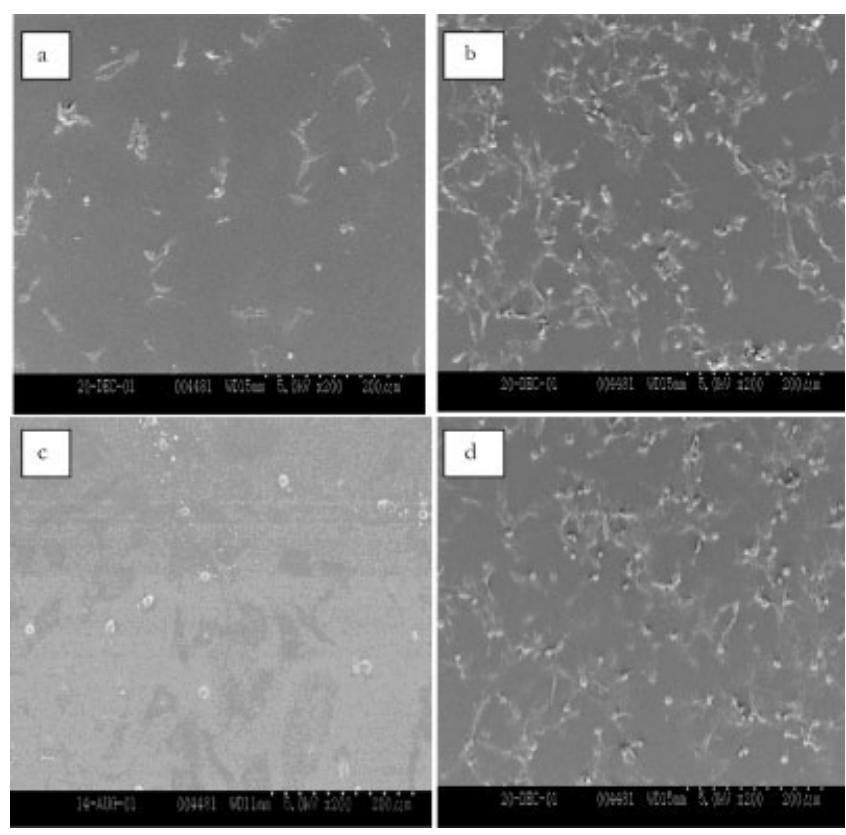

Figure 6. SEM micrographs $(\times 200)$ of endothelial cell adhering on as obtained DLC and a-C:H:Si thin films. Cells were seeded at the same time under same conditions as that of the Nitrogen doped samples above. (a) DLC, (b) SD5, (c) uncoated Si-wafer, and (d) SD15.

V). This finding is not surprising based on the higher energy associated with the ionic species, which could increase the reaction rate, bond breaking, and covalent bond formation. This is suggested to be contributory to the difference in the contact angle results and the endothelial interaction. NEXAFS and other studies may be useful in establishing further differences existing, since nitrogen and carbon atoms are both multivalent, each with a possibility of forming $\mathrm{sp}^{1}, \mathrm{sp}^{2}$ and or $\mathrm{sp}^{3}$ hybridization, making a total of nine different configurations. The effect of the charges of the $\mathrm{N}$-doping specie on the bonding configuration and on the endothelial cellular interaction requires further investigation.

\section{CONCLUSION}

Human microvascular cellular interaction with $\mathrm{N}$-species (ions excluded) doped a-C:H and other a-C:H doped hybrids ( $\mathrm{Si}-$ doped and doping with $\mathrm{N}$ atoms plus ions) has been examined by Raman, XPS, and contact angle techniques. More hydrophobic films, with some exceptions, seem favorable for endothelial cellular interaction. It seems difficult, however, to establish at this stage a relationship between Raman PL (indicating mainly $\mathrm{sp}^{3}$ coordination bond) and endothelial cellular interaction. Instead the $\mathrm{sp}^{2}$ clusters sizes, graphitization, and the $\mathrm{sp}^{2} / \mathrm{sp}^{3}$ ratios could be more important in these interactions rather than absolute $\mathrm{sp}^{3}$ value. It seems evident that $\mathrm{N}$-doping increases the Raman $I_{\mathrm{D}} / I_{\mathrm{G}}$ ratios, whereas $\mathrm{N}$-doping with $\mathrm{N}$-species where ions were excluded decreases it slightly and Si-doping decreases it even further. In this study, lower Raman $I_{\mathrm{D}} / I_{\mathrm{G}}$ ratios are associated with increased $\mathrm{sp}^{3} / \mathrm{sp}^{2}$ ratio, increased $\mathrm{H}$ concentration, increased PL intensity, and a higher endothelial cellular adhesion in the Si-DLC films, but not necessarily so with the $\mathrm{N}$-doped films where either slight increase or decrease in the $I_{\mathrm{D}} / I_{\mathrm{G}}$ ratios, PL intensity, and $\mathrm{sp}^{3} / \mathrm{sp}^{2}$ ratio improved endothelial attachment. This work requires further investigations and these investigations are relevant to biocompatibility assessment of nanostructured biomaterials and tissue engineering research/development.

The authors acknowledge the provision of the RF plasma source by the SVT Associates of Eden Prairie, MN, USA.

\section{REFERENCES}

1. Grischke M, Hieke A, Morgenweck F, Dimigen H. Variation of the wettability of DLC-coatings by network modification using silicon and oxygen. Diamond Rel Mater 1998;7:454-458.

2. Ogwu AA, Magill D, Maguire P, McLaughlin J, McCullough RW, Voulot D. Nitrogen doping of amorphous DLC films by rf plasma dissociated nitrogen atom surface bombardment in a vacuum. Surf Eng 2000;16:427-430.

3. Demichelis F, Pirri CF, Tagliaferro A. Influence of silicon on the physical properties of diamond-like carbon. Mater Sci Eng B 1992;11:313-316.

4. Okpalugo TIT, Maguire PD, Ogwu AA, McLaughlin JA. The effect of silicon doping and thermal annealing on the electrical and structural properties of hydrogenated amorphous carbon thin films. Diamond Rel Mater 2004;13:1549-1552.

5. Okpalugo TIT, Ogwu AA, Maguire PD, McLaughlin J. Platelet adhesion on silicon modified hydrogenated amorphous carbon films. Biomaterials 2004;25:239-245.

6. Okpalugo TIT, Ogwu AA, Maguire PD, McLaughlin J. In-vitro blood compatibility of ultra-smooth a-C:H:Si and a-C:H thin films. Diam Rel Mater 2004;13:1088-1092.

7. Voulot D, McCullough RW, Thompson WR, Burns D, Geddes J, Cosimini GJ, Nelson E, Chow PP, Klaassen J. Determination of atomic nitrogen flux from a radio frequency plasma nitride source for molecular beam epitaxy systems. J Vac Sci Technol A 1998;16:3434-3437.

8. Wilcox DC, Dove BS, McDavid DW, Greer DB. Imagetool. UTHSCSA, 1996. http://ddsdx.uthscsa.edu/dig/itdesc.

9. Ray SC, Okpalugo TIT, Tsai HM, Chiou JW, Pong WF, Wang WJ, Papakonstantinou P, McLaughlin JA. Electronic structure and photoluminescence study of Silicon doped diamond like carbon (Si-DLC) thin films. Mater Res Bulletin, 2005;40(10): 1757-1764.

10. Milne WI, Robertson J. Band model for electron field emission from diamond and diamond-like carbon. Mater Res Soc Symp Proc 1997;471:217.

11. Magill DP, Ogwu AA, Mclaughlin JA, Maguire PD, McCullough RW, Voulot D, Gillen D. Electrical characteristics of nitrogen incorporated hydrogenated amorphous carbon. J Vac Sci Technol A 2001;19:2456-2462.

12. Robertson J. Diamond-like amorphous carbon. Mater Sci Eng R 2002;37:129-281.

13. Kaukonen M, Nieminen RM, Poykko S, Settsonen A. Phys Rev Lett 1999;83:5346.

14. Matsuda T, Kurumatani H. Surface induced in vitro angiogenesis: Surface property is a determinant of angio-genesis. ASAIO Trans 1990;36:M565-M568.

15. Hubbell JA, Massia SP, Drumheller PD. Surface-grafted cellbinding peptides in tissue engineering of vascular graft. Ann NY Acad Sci 1992;665:253-258. 